\title{
Substantial Protective Immunity Conferred by a Combination of Brucella abortus Recombinant Proteins against Brucella abortus 544 Infection in BALB/c Mice
}

\author{
Lauren Togonon Arayan, Tran Xuan Ngoc Huy, Alisha Wehdnesday Bernardo Reyes, Huynh Tan Hop, \\ Vu Hai Son, WonGi Min, Hu Jang Lee, and Suk Kim* \\ Institute of Animal Medicine, College of Veterinary Medicine, Gyeongsang National University, Jinju 52828, Republic of Korea
}

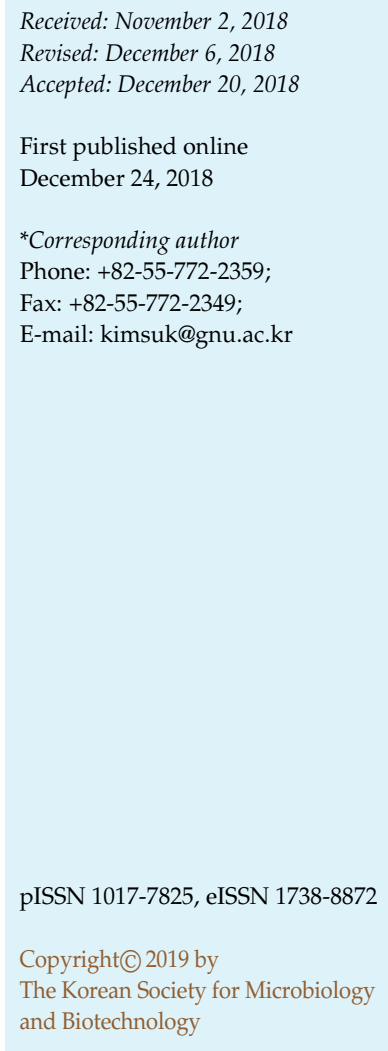

\begin{abstract}
Chronic infection with intracellular Brucella abortus (B. abortus) in livestock remains as a major problem worldwide. Thus, the search for an ideal vaccine is still ongoing. In this study, we evaluated the protective efficacy of a combination of $B$. abortus recombinant proteins; superoxide dismutase (rSodC), riboflavin synthase subunit beta (rRibH), nucleoside diphosphate kinase (rNdk), 50S ribosomal protein (rL7/L12) and malate dehydrogenase $(\mathrm{rMDH})$, cloned and expressed into a pMal vector system and $\mathrm{DH} 5 \alpha$, respectively, and further purified and applied intraperitoneally into BALB/c mice. After first immunization and two boosters, mice were infected intraperitoneally (IP) with $5 \times 10^{4}$ CFU of virulent B. abortus 544 . Spleens were harvested and bacterial loads were evaluated at two weeks post-infection. Results revealed that this combination showed significant reduction in bacterial colonization in the spleen with a log protection unit of 1.31, which is comparable to the average protection conferred by the widely used live attenuated vaccine RB51. Cytokine analysis exhibited enhancement of cell-mediated immune response as IFN- $\gamma$ is significantly elevated while IL-10, which is considered beneficial to the pathogen's survival, was reduced compared to control group. Furthermore, both titers of IgG1 and IgG2a were significantly elevated at three and four-week time points from first immunization. In summary, our in vivo data revealed that vaccination with a combination of five different proteins conferred a heightened host response to Brucella infection through cell-mediated immunity which is desirable in the control of intracellular pathogens. Thus, this combination might be considered for further improvement as a potential candidate vaccine against Brucella infection.
\end{abstract}

Keywords: B. abortus, recombinant proteins, vaccination, cytokines, protection

\section{Introduction}

B. abortus is a Gram-negative, facultative intracellular parasite that infects a wide range of domestic animals such as cattle, small ruminants and humans [1]. Brucellosis still remains an important zoonosis in developing countries and in particular, causes about 500,000 cases worldwide each year [2,3]. Among the species of Brucella, B. abortus, which is responsible for brucellosis in cattle, is considered to be a major pathogen that provokes clinical brucellosis in humans [4]. This zoonotic pathogen proliferates within professional phagocytes that often lead to chronic infection $[5,6]$. Its ability to circumvent the bactericidal mechanisms of macrophages is key to its virulence $[6,7]$.

Recent advances in the development of brucellosis vaccine are still underway. The availability of current live attenuated vaccines for animals such as RB51 and B. abortus strain 19 pose risk in humans, thus, handling and strict adherence to vaccination protocols are required [8,9]. Another approach proven to be beneficial in the elimination of brucellosis in some U.S. states is identification of infected animals proceeded by culling and immunization 
of uninfected animals, which may not be applicable in other countries due to cultural reasons $[8,9]$. The search for the ideal vaccine will continue to be an imminent goal in the field of vaccine research for the eradication of brucellosis. More importantly, the absence of human vaccines raises the need to control brucellosis in reservoir animals which can be achieved by development of vaccines that offer efficacy and safety in both animals and humans $[10,11]$. Many efforts have been raised in the development of vaccine strategies intended for intracellular pathogens which proved to be more difficult. One approach has been the use of recombinant vaccine of which success is highly dependent on the ability of individual purified antigens of specific pathogens to elicit appropriate cell-mediated immune responses to eradicate intracellular infections [12].

Preliminary evaluation in the selection of potential Brucella vaccines in livestock includes categories that manifest cytokine profiles reflective of Th1 dominance as previously reported. This includes predominance in the production of TNF and IFN- $\gamma$ as crucial cytokines in the intracellular killing of B. abortus. Although selection of potential vaccines is based upon results obtained from the mouse model and mouse responses may not always be reflective of other animals, considering this index may still be considered helpful $[13,14]$.

In this study, we evaluated the protective efficacy of a combination of five selected B. abortus recombinant proteins that were previously reported to be individually immunogenic and able to induce protective immunity using various adjuvants in a murine model. We have previously characterized the immunogenicity of two of the components of this vaccine combination; recombinant protein $\mathrm{Ndk}$ (nucleoside diphosphate kinase) and $\mathrm{rMDH}$, which were cloned into a pMal vector system [1, 15]. These proteins showed immunoreactivity with $B$. abortus-positive mouse sera while the protein MBP (Maltose-binding protein) encoded by the vector system is non-reactive with both $B$. abortus-negative and -positive mouse sera. Previously identified immunogenic recombinant proteins were cloned and added to this combination, namely; recombinant $\mathrm{RibH}$ which has been depicted to be highly immunogenic through a three-dimensional analysis revealing a pentameric structure that is specifically suggestive of immunogenicity [16], rSodC ( $\mathrm{Cu}-\mathrm{Zn})$, previously evaluated as a peptide vaccine [17], and rL7/L12, which displayed a T-helper 1 immune response upon evaluation with murine CD4+ T cells [18]. Although the protective efficacy of rMDH has not yet been proven in vivo, its high immunogenicity in Brucella-positive bovine and mouse sera at different stages of infection was considered for its inclusion in this combination vaccine [15].

\section{Materials and Methods}

\section{Bacterial Strains}

Wild-type strains derived from B. abortus 544 (ATCC 23448), a smooth, virulent $B$. abortus biovar 1 strain, were cultivated in either Brucella broth (Becton Dickinson, USA) or on Brucella agar. Bacteria were cultured at $37^{\circ} \mathrm{C}$ with vigorous shaking until they reached stationary phase. Escherichia (E.) coli $\mathrm{DH} 5 \alpha$ was purchased from Invitrogen (USA) and used for creating plasmid constructs. E. coli $\mathrm{DH} 5 \alpha$ culture was routinely grown at $37^{\circ} \mathrm{C}$ in LB broth or agar supplemented with $100 \mu \mathrm{g} / \mathrm{ml}$ of ampicillin (Sigma, USA).

\section{Recombinant Expression and Protein Purification}

The sequences of the five B. abortus genes were amplified using PCR (Table 1). Cloning and expression of the recombinant proteins were conducted according to a previous study into a pMAL vector system [1]. Recombinant proteins were expressed in

Table 1. Primer sequences used for cloning B. abortus recombinant proteins.

\begin{tabular}{|c|c|c|c|c|}
\hline Gene & Forward primer & Reverse primer & $\begin{array}{l}\text { Restriction enzyme } \\
\text { (forward) }\end{array}$ & $\begin{array}{l}\text { Restriction enzyme } \\
\text { (reverse) }\end{array}$ \\
\hline $\mathrm{ribH}$ & $\begin{array}{l}5^{\prime} \text { ACC GGA TCC ATG AAC CAA } \\
\text { AGC TGT CCG AAC } 3^{\prime}\end{array}$ & $\begin{array}{l}5^{\prime} \text { AGC CTG CAG CGG CTG CGC TCG } \\
\text { CTC ACG ATC } 3^{\prime}\end{array}$ & $\mathrm{Bam} / \mathrm{HI}$ & PstI \\
\hline SodC & 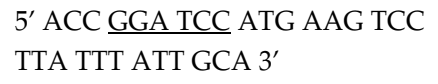 & $\begin{array}{l}5^{\prime} \text { AGC CTG CAG TTA TTC GAT CAC } \\
\text { GCC GCA GGC } 3^{\prime}\end{array}$ & $\mathrm{Bam} / \mathrm{HI}$ & PstI \\
\hline ndk & $\begin{array}{l}\text { 5' CGC GGA TCC ATG GCA ATT } \\
\text { GAA CGTACGC 3' }\end{array}$ & $\begin{array}{l}\text { 5' GGC CTG CAG TCA GCC AAC GAT } \\
\text { TTC GGT 3' }\end{array}$ & $\mathrm{Bam} / \mathrm{HI}$ & PstI \\
\hline L7/L12 & $\begin{array}{l}5^{\prime} \text { AGC TCT AGA ATG GCT GAT } \\
\text { CTC GCA AAG ATC } 3^{\prime}\end{array}$ & $\begin{array}{l}5^{\prime} \text { ATC CTG CAG C TTA CTT GAG TTC } \\
\text { AAC CTT GGC } 3^{\prime}\end{array}$ & $\mathrm{XBaI}$ & PstI \\
\hline mdh & $\begin{array}{l}5^{\prime} \text { ATT TC GGA TCC ATG GCA } \\
\text { CGC AAC AAG ATT } 3^{\prime}\end{array}$ & $\begin{array}{l}5^{\prime} \text { AGGC GTC GAC TTA TTT CAG CGA } \\
\text { CGG ACG 3' }\end{array}$ & $\mathrm{Bam} / \mathrm{HI}$ & SalI \\
\hline
\end{tabular}

${ }^{*}$ Footnote-Enzyme recongnition sequences are underlined. 
E. coli $\mathrm{DH} 5 \alpha$, induced in LB broth supplemented with $100 \mu \mathrm{g} / \mathrm{ml}$ ampicillin, $0.2 \%$ glucose and varying IPTG concentrations of $0.1-$ $0.5 \mathrm{mM}$ at $37^{\circ} \mathrm{C}$ for $4 \mathrm{~h}$. E. coli cells were harvested at 5,000 $\times g$ for $10 \mathrm{~min}$ and resuspended in $25 \mathrm{ml}$ column buffer $(20 \mathrm{mM}$ Tris $\mathrm{HCl}$, $1 \mathrm{mM}$ EDTA, $200 \mathrm{mM} \mathrm{NaCl}, 10 \%$ glycerol, $\mathrm{pH}$ 7.4). The lysates were subjected to a freeze-thaw cycle thrice and sonicated (Bandelin electronic, Germany) at $10,000 \mathrm{~Hz}$ on ice for $15 \mathrm{~min}$. The supernatant was centrifuged at 5,000 $\times g$ for $20 \mathrm{~min}$, filtered through $0.45 \mu \mathrm{m}$ (Minisart, Sigma Aldrich, USA) and loaded into a maltose resin column (Bio-Rad Laboratories, USA). Finally, purified proteins were eluted with $10 \mathrm{mM}$ maltose in column buffer.

\section{Sodium Dodecyl Sulfate-Polyacrylamide Gel Electrophoresis} (SDS-PAGE) and Western Blot Analysis

Induced cells were lysed and purified products were boiled at $100^{\circ} \mathrm{C}$ for $5 \mathrm{~min}$ in $2 \times$ SDS buffer ( $4 \%$ SDS, 10\% 2-mercaptoethanol, $20 \%$ glycerol, $0.004 \%$ bromophenol blue and $0.125 \mathrm{M}$ Tris $\mathrm{HCl}, \mathrm{pH}$ 6.8) subjected to SDS-PAGE $[19,20]$. Following gel electrophoresis, separated proteins were subjected to western blot analysis. Proteins were transferred to Immobilon-P membranes (Milipore, USA) emerged in transfer buffer ( $25 \mathrm{mM}$ Tris, $190 \mathrm{mM}$ glycine, $20 \%$ methanol, $\mathrm{pH} 8.3$ ) for 30 min using ATTO Semi-dry transfer machine (WSE-7210, Japan). Membranes were blocked in 5\% skim milk at room temperature (Difco, USA) for $30 \mathrm{~min}$, washed with $0.05 \%$ Tween-20 (PBS-T) and incubated with Brucella-positive or Brucella-negative mouse sera (sera collected from mouse infected with virulent B. abortus (1:10000 dilution) at $4^{\circ} \mathrm{C}$, overnight. Following incubation with mouse sera, the membranes were washed and incubated with horseradish peroxidase-conjugated goat anti-mouse IgG antibody (1:1000 dilution) (Sigma, USA) for $1 \mathrm{~h}$ at room temperature, washed, detected with ECL solution (Thermo Scientific, USA) and finally analyzed with a Molecular Imager ChemiDoc XRS+ system machine (Bio-Rad Laboratories).

\section{Immunization and Bacterial Challenge}

The protective effect of a combination of recombinant proteins; SodC, RibH, Ndk, L7/L12 and MDH was evaluated. Twenty, tenweek-old female BALB/c mice (Japan SLC, Japan) were allocated to four groups. All groups of mice were intraperitoneally injected with 1:1 volume ratio of recombinant protein and incomplete Freund's adjuvant (IFA) (Sigma) in a total volume of $200 \mu$ l. The groups of five mice each were immunized IP with PBS, maltosebinding protein $(\mathrm{MBP})(100 \mu \mathrm{g}), \mathrm{RB} 51\left(1 \times 10^{6} \mathrm{CFU}\right)$ or a combination of five B. abortus recombinant proteins $(20 \mu \mathrm{g}$ each for a total of $100 \mu \mathrm{g}$ ) on weeks 0,2 , and 3 . Serum samples were collected via tail vein on weeks 3 and 4 after the first immunization. A week after the last immunization, mice were IP challenged with approximately $5 \times 10^{4} \mathrm{CFU}$ of B. abortus in $100 \mu \mathrm{l}$ PBS

\section{Ethical Approval}

The method of handling and sacrifice conducted in this experiment was approved by the Animal Ethical Committee of
Gyeongsang National University (Authorization Number GNU170331-M0017).

\section{Cytokine and Humoral Immune Responses}

The levels of IL-12p70, IL-10, IFN- $\gamma$, TNF, MCP-1, and IL-6 in sera were determined by cytometric bead array (BD CBA Mouse Inflammation Kit, USA) and analyzed using a FACS Calibur flow cytometer (BD Biosciences, USA). On the other hand, IgG1 and IgG2a isotypes were measured through indirect ELISA. Briefly, purified proteins were diluted in coating buffer (carbonate buffer; $\mathrm{pH}$ 9.6) comprising $1.5 \mu \mathrm{g} / \mathrm{ml}$ of each protein, coated into a 96well plate (Maxibinding, SPL Life Sciences, Korea) in $100 \mu \mathrm{l}$ per well followed by overnight incubation at $4^{\circ} \mathrm{C}$. The wells were washed with $0.5 \%$ PBS-T and blocked with $5 \%$ skim milk in PBS-T at room temperature for $2 \mathrm{~h}$. The wells were then incubated with sera in blocking buffer at dilutions reaching cut off values. The wells were washed and incubated with HRP-conjugated IgG1 or IgG2a (Abcam, USA) for $1 \mathrm{~h}$. Finally, the wells were washed and O-phenyldiamine (OPD) was added into the wells and the absorbance was read after $15 \mathrm{~min}$ at $450 \mathrm{~nm}$ through an ELISA reader (Biotek, Korea). Cut-off value was computed as the mean specific OD plus standard deviation for non-immunized mice diluted at 1:100 [1]. Titers were determined as the reciprocal value of the dilution that yields an absorbance higher than the cut off value.

\section{Bacterial Clearance Efficiency}

The protective effect of the combined vaccine was evaluated as previously reported [1]. Mice were sacrificed via cervical dislocation at two weeks post-infection. Spleens were collected, weighed and homogenized in PBS. Homogenized spleens were serially diluted, plated on Brucella agar and incubated at $37^{\circ} \mathrm{C}$ for 3 days. Log protection was computed as the mean $\log _{10} \mathrm{CFU}$ of PBS group minus $\log _{10}$ CFU of the vaccinated group. Finally, the $\log _{10}$ (number of CFUs/g) was calculated.

\section{Statistical Analysis}

The results for each experiment are expressed as the mean \pm SD. One-way ANOVA program was utilized in all assays.

\section{Results}

\section{Protein Purification and Immunoreactivity of Recombinant Proteins}

After induction and purification steps, purified proteins were analyzed via SDS to check for target molecular masses. The approximate molecular masses for recombinant proteins; SodC, RibH, Ndk, L7/L12, and $\mathrm{MDH}$ were approximately $68.1,67.3,65.27,62.5$, and $73 \mathrm{kDa}$, respectively (Fig. 1A). Immunoblot analysis showed immunoreactivity of rSodC, rRibH, rNdk, rL7/L12, and rMDH with both Brucella-positive (Fig. 1B), and -negative mouse sera (Fig. 1C). 


\section{A}
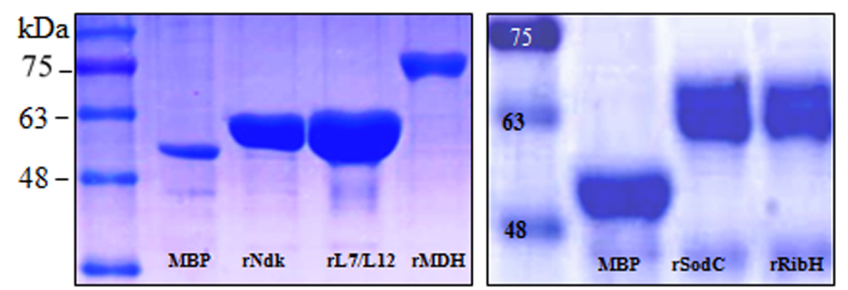

B
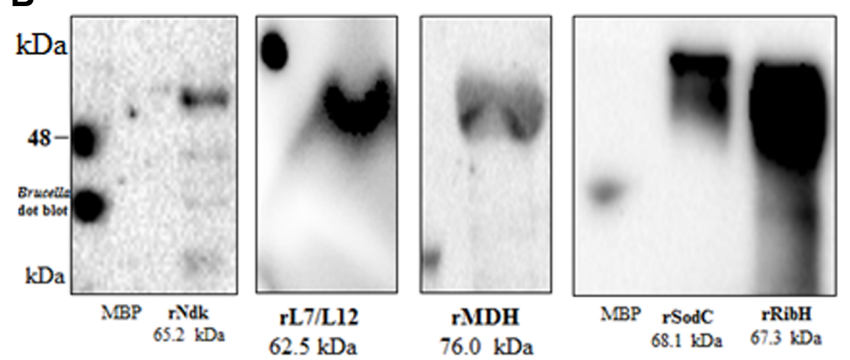

C

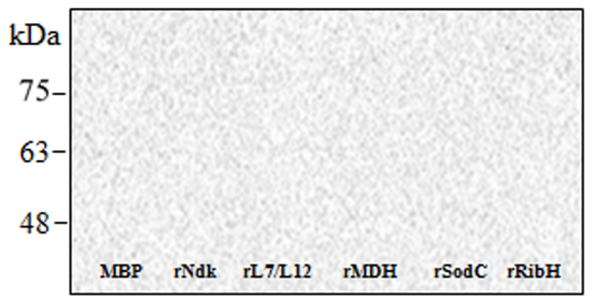

Fig. 1. Expression and immunoreactivity of purified B. abortus recombinant proteins.

SDS-PAGE analysis of purified proteins stained with Coomasie Brilliant Blue (A) Immunogenicity of each recombinant protein against Brucella-positive mouse sera (B) or -negative mouse sera (C). B. abortus dot blots are provided as reference for determining molecular weight.

Consistent with previous data, MBP did not react with either Brucella-positive or -negative mouse sera (Figs. 1B and $1 C)$.

\section{Combined Recombinant Vaccine Engendered Significant Protection against Brucella Infection}

The rate of infection was assessed by measuring CFU in the spleen two weeks post-infection. The mean $\log _{10} \mathrm{CFU}$ of the spleen of the combined protein-immunized group was significantly reduced than with the PBS $(p<0.01)$ or MBP groups $(p<0.05)$ (Fig. 2A), demonstrating a log protection unit of approximately 1.31 over the PBS or MBP groups. The CFU of the MBP group was not significantly different from the PBS group. Furthermore, the weight of the spleen was also reduced compared with the PBS or MBP groups
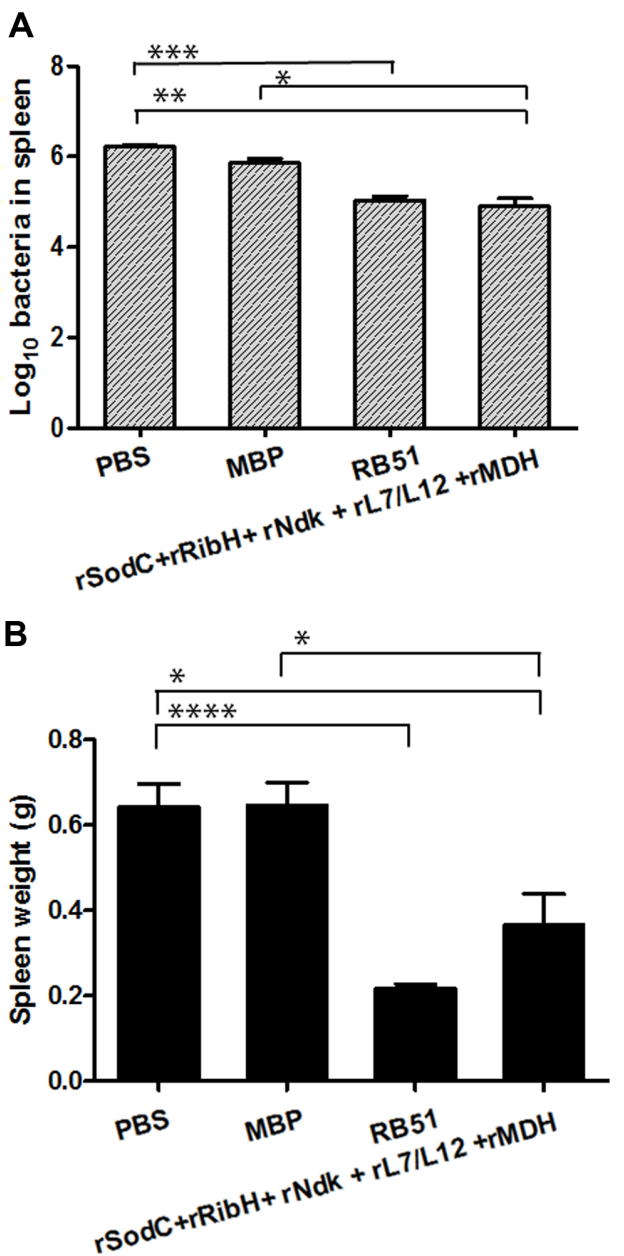

Fig. 2. Degree of protection conferred by the administration of combined recombinant proteins against a virulent strain of B. abortus.

Protection log unit in the combined protein-immunized group (A). Reduction in the weight of the spleen in the combined immunized group (B). rSodC+rRibH+rNdk+rL7/L12+rMDH: Combination of B. abortus recombinant proteins $(\mathrm{Cu}-\mathrm{Zn}$ superoxide dismutase, riboflavin synthase subunit beta, nucleoside diphosphate kinase, $50 \mathrm{~S}$ ribosomal protein and malate dehydrogenase). Statistical differences are analyzed from the values of the PBS (non-immunized group). Asterisks indicate significant difference: ${ }^{*} p<0.05,{ }^{* *} p<0.01,{ }^{* * *} p<$ $0.001,{ }^{* * * *} p<0.0001$.

$(p<0.05)$ (Fig. 2B). Although higher log protection units are established in previous studies, the log protection unit provided by the attenuated live RB51 vaccine in the current study is consistent with other studies demonstrating a 1.4 $\log$ protection unit in BALB/c mice with B. abortus 544 infection [21] and 1.26 with B. abortus 2308 infection [22]. 


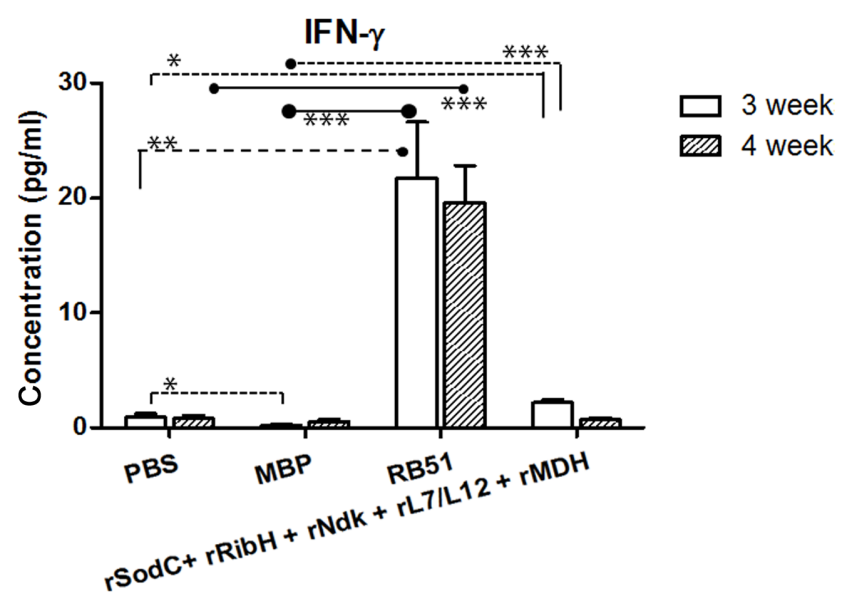

Fig. 3. IFN- $\gamma$ concentration $(\mathrm{pg} / \mathrm{ml})$ in the sera of mice challenged with $B$. abortus infection at 3- and 4-week time point after first immunization.

rSodC+rRibH+rNdk+rL7/L12+rMDH: Combination of B. abortus recombinant proteins $(\mathrm{Cu}-\mathrm{Zn}$ superoxide dismutase, riboflavin synthase subunit beta, nucleoside diphosphate kinase, $50 \mathrm{~S}$ ribosomal protein and malate dehydrogenase). Asterisks indicate significant difference: ${ }^{*} p<0.05,{ }^{* *} p<0.01,{ }^{* * *} p<0.001$.

\section{Combined Antigens Induce Substantial Th1 Immune Response}

The production of (Th1)-type, cell-mediated immunity cytokines that is responsible for anti-Brucella activities such as macrophage and lymphocyte activation for intracellular killing is an established protective immunity mechanism in

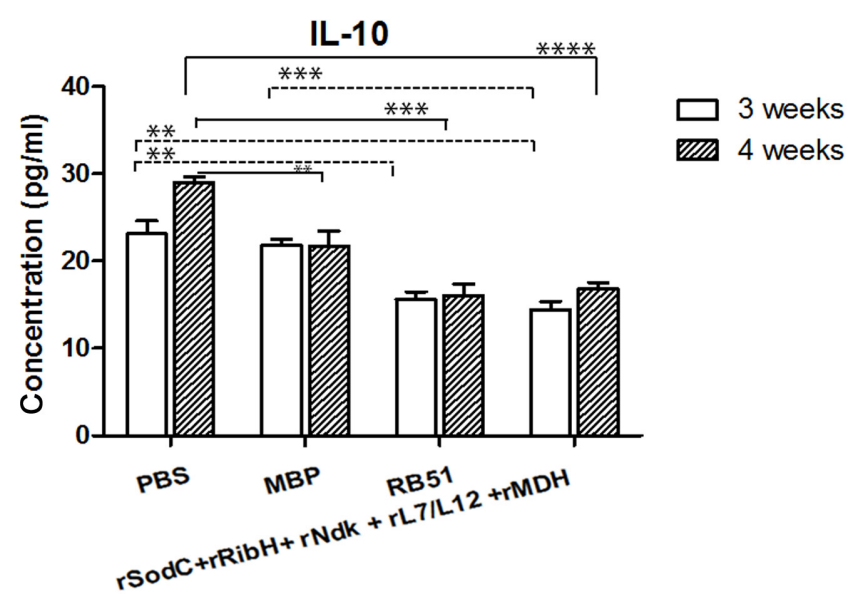

Fig. 4. IL-10 concentration $(\mathrm{pg} / \mathrm{ml})$ in the sera of mice challenged with $B$. abortus infection at 3- and 4-week time point after first immunization.

rSodC+rRibH+rNdk+rL7/L12+rMDH: Combination of B. abortus recombinant proteins $(\mathrm{Cu}-\mathrm{Zn}$ superoxide dismutase, riboflavin synthase subunit beta, nucleoside diphosphate kinase, $50 \mathrm{~S}$ ribosomal protein and malate dehydrogenase). Asterisks indicate significant difference: ${ }^{*} p<0.05,{ }^{* *} p<0.01,{ }^{* * *} p<0.001,{ }^{* * * *} p<0.0001$.

the murine model $[23,24]$. In this study, cytokines in the sera were measured and have shown that the PBS and MBP groups did not elicit production of IFN- $\gamma$ and exhibited increased levels of IL-10 while the combined proteinimmunized group substantially produced 2.3-fold $(p<0.05)$ and 10-fold $(p<0.001)$ increases of IFN- $\gamma$ over PBS and
A

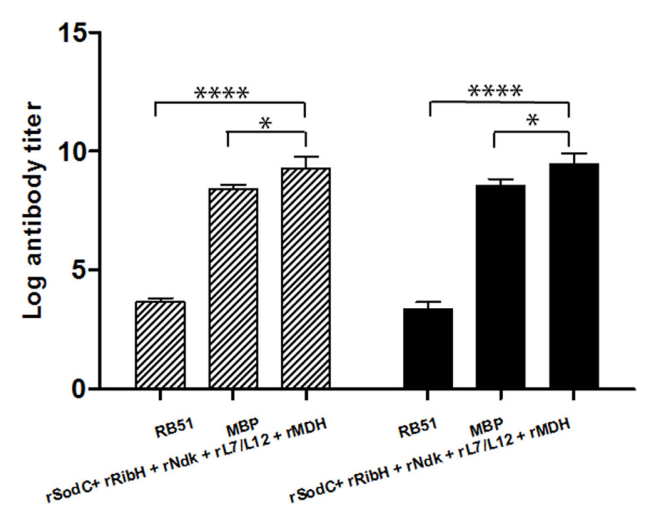

B

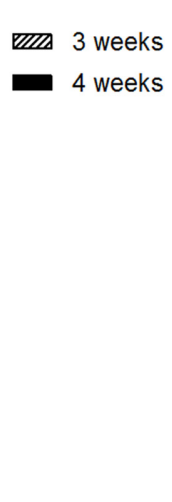

$\lg \mathbf{G a}$

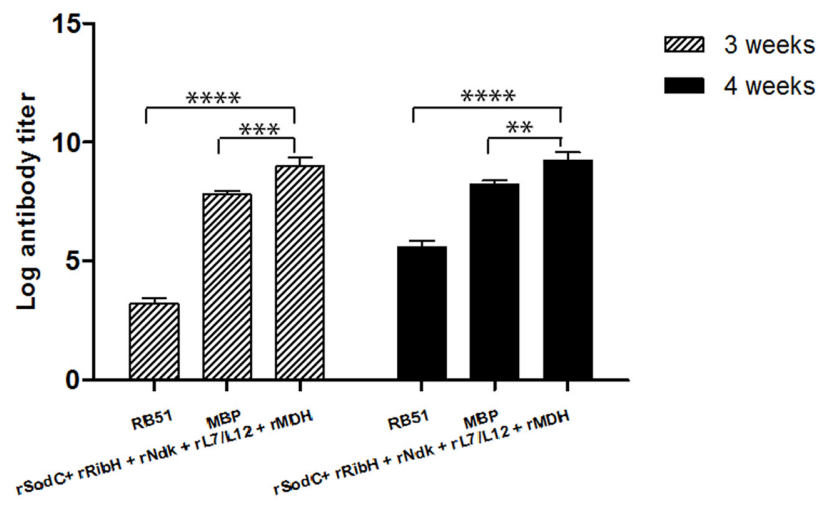

Fig. 5. Humoral immune response in the combined protein-immunized group.

The levels of IgG1 (A) and IgG2a (B) elicited by the combined protein-immunized group after 3- and 4-week time points after the first immunization were determined by ELISA. Mice infected with $1 \times 10^{6} \mathrm{RB} 51$ were included as positive control. $\mathrm{rSodC}+\mathrm{rRibH}+\mathrm{rNdk}+\mathrm{rL7} /$ L12+rMDH: Combination of B. abortus recombinant proteins (Cu-Zn superoxide dismutase, riboflavin synthase subunit beta, nucleoside diphosphate kinase, $50 \mathrm{~S}$ ribosomal protein and malate dehydrogenase). Data are represented as the mean $\pm \mathrm{SD}(n=5$ mice/group). Asterisks indicate significant difference: ${ }^{*} p<0.05,{ }^{* *} p<0.01,{ }^{* * *} p<0.001,{ }^{* * * *} p<0.0001$. 
MBP, respectively at three weeks post-immunization (Fig. 3). Interestingly, vaccination with RB51 resulted in an extreme elevation of 23.5-fold and 106-fold increases in IFN- $\gamma$ compared with the PBS and MBP groups, respectively, at three weeks post-immunization and 24.8-fold and 76.5fold increases compared with PBS and MBP groups, respectively, at four weeks post-immunization (Fig. 3). On the other hand, 1.6-fold and 1.7-fold decreased levels of IL10 over PBS and MBP, respectively, (Fig. 4) were observed at three weeks post-immunization $(p<0.01)$. At four weeks post-immunization, levels of IL-10 declined significantly compared with the PBS group $(p<0.0001)$. IL-12p70, IL-6, MCP-1, and TNF were not significantly different across all groups.

\section{Humoral Immune Response in Combination Protein Immunized Mice}

The presence of $\mathrm{rSodC}, \mathrm{rRibH}, \mathrm{rNdk}, \mathrm{rL7} / \mathrm{L12}$, and rMDH-specific antibodies in the sera of mice collected at three and four weeks post-immunization was analyzed through ELISA. As shown in Figs. 5A and 5B, combined antigens elicited significant levels of both IgG1 $(p<0.05)$ and $\operatorname{IgG} 2 \mathrm{a}(p<0.001)$ at three weeks post-immunization. Similarly, at four weeks post-immunization, both IgG1 $(p<0.05)$ and IgG2a $(p<0.01)$ were shown to be elevated compared to the MBP group. The ratio of IgG2a/IgG1 at three and four weeks post-immunization was approximately 1.0. The titer for the live vaccine strain RB51 was also found to induce a lower humoral immune response compared to the combined protein-immunized group. Consistent with previous studies, the PBS group did not induce humoral immunity (data not shown).

\section{Discussion}

The search for the ideal vaccine will continue to be the primary goal in the effort to eradicate brucellosis as vaccination still remains the most efficient method in the control of this infectious agent. RB51, a widely used live attenuated vaccine, offers major advantages such as noninterference in the diagnosis of brucellosis, however it also causes residual virulence in both animals and humans [25]. Several antigenic proteins such as periplasmic, cytoplasmic, inner and outer membranes have been previously identified according to previous studies.

It is our goal in this study to evaluate the potential of these single immunogenic recombinant proteins hypothesized to confer superior protection against Brucella infection when given as a combination using a mouse model.
Constituents of the vaccine combination have been selected based on the protective efficacy of individual proteins as previously reported. Thus, five recombinant proteins encoded by B. abortus SodC, ribH, ndk, L7/L12 and mdh genes were selected and combined. Immunization with recombinant L7/L12 ribosomal protein had been characterized earlier to be an important immunogenic antigen that elicits primarily Th1 response specifically manifested with an elevated level of IFN- $\gamma$ [18]. Substantially, immunization with $\mathrm{rL7} / \mathrm{L} 12$ led to an average protective log reduction of 1.0 when compared to the B. abortus S19vaccinated group [18]. Another important feature of this protein is that it is capable of eliciting delayed-type hypersensitivity [26]. On the other hand, rSodC has been conclusively established to be responsible for bacterial survival against oxidative killing by catalyzing dismutation of superoxide as a by-product of the process of phagocytosis in host macrophages [27]. Given the function of this molecule, SodC is considered to be an important virulence determinant in Brucella infection [28]. This has also been found to be consistent with other bacteria including Mycobacterium tuberculosis [29] and Salmonella enterocolitica serovar Typhimurium [30]. RibH is a cytoplasmic protein that induces Th1-type responses leading to a notable protection upon $B$. abortus infection in mice when utilized as a DNA and recombinant vaccine $[31,16]$. B. abortus $\mathrm{rMDH}$ and $\mathrm{rNdk}$ were determined as immunogenic antigens through a two-dimensional electrophoresis (2DE) assay against $B$. abortus-infected cattle sera and immunoblot assay against $B$. abortus-infected mouse sera. The latter was further investigated as recombinant vaccine in a mouse model revealing a significant protective efficacy [1]. In this study, all the recombinant Brucella proteins individually demonstrated immunoreactivity with Brucella-positive mouse sera. We have also shown that immunization with a combination of rSodc and $\mathrm{rRibH}$ revealed a marked protective immunity in Brucella-infected BALB/c mice (unpublished data). Obtaining an ideal vaccine for the control of brucellosis requires an immune response that is geared towards a cell-mediated (Th1) type immunity that involves CD8+ and CD4+ T lymphocytes, T-helper cells producing key cytokines IFN- $\gamma$, IL-12 and TNF $\alpha$ and activated macrophages $[32,33]$. The current study exhibited substantial levels of 2.3-fold increase of IFN- $\gamma$ in the combined protein-immunized group which is considered principal for the activation of macrophages leading to an enhanced bactericidal killing [34, 35]. The anti-Brucella ability of IFN- $\gamma$-activated macrophages is mainly attributed to a magnified production of reactive oxygen intermediates 
in vitro [36]. Other than activation of macrophages, IFN- $\gamma$ also activates cytotoxic CD8+ T-cells and stimulates activated plasma B cells to produce IgG2a isotypes [37, 38]. In reference to an established immune response to RB51, which is also consistent with our data showing an approximate 100-fold increase in IFN- $\gamma$, we can conclude that the significant elevation of IFN- $\gamma$ mounted in the combined protein-immunized group at three weeks postimmunization basically demonstrates a Th1-type response which is ideal and desirable in the control of facultative intracellular pathogens. Th1 immunity is also characterized by IgG2a production while Th2 immunity is distinguished by IgG1 and IgE responses [16, 39, 40]. Although humoral (Th2) immunity is of lesser importance in brucellosis control [32, 33], the combined protein-immunized group elicited high levels of both IgG1 and IgG2a with IgG2a/ IgG1 ratio of approximately 1.0 at three and four weeks post-immunization which is highly suggestive of Th1 immunity. A previous study had demonstrated mixed Th1 and Th2 responses upon immunization with recombinant Brucella lumazine synthase which led to decreased bacterial susceptibility in BALB/c mice [16]. In this study, production of IL-10 is significantly attenuated in the combined proteinimmunized group at three and four weeks postimmunization. IL-10 is a cytokine of the Th2 branch with a bivalent function. It regulates excessive proinflammatory responses that are characterized in Gram-negative infections but also inhibits responses of the CD8+ and Th1 immunity [41]. Neutralization of IL-10 reduced bacterial proliferation in the spleens 10-fold lower in BALB/c mice challenged with B. abortus strain 2308 and furthermore dampens the anti-Brucella functions of activated macrophages despite the abundance of IFN- $\gamma$ [42]. In addition, it also diminishes the ability of spleen cells to produce IFN- $\gamma$ upon stimulation of antigens in Brucella [42] and consequently stimulates generation of IFN- $\gamma$ and IL-17 as well as TNF- $\alpha$ in splenic cells [43]. The 1.6-1.7-fold inhibition in the levels of IL-10 in the combined protein-immunized group could have promoted induction of significant levels of IFN- $\gamma$ that heightened its resistance against Brucella infection. The combination of B. abortus recombinant proteins: SodC, RibH, Ndk, L7/L12 and MDH clearly exhibited a cellmediated immune response which is a primary category in the initial screening of candidate vaccines. Although higher $\log$ protection units of RB51 are established in previous studies, the log protection unit provided by the live attenuated RB51 vaccine in our current and previous data is within 1.07-1.27 which is consistent with other studies demonstrating 1.4-log protection unit in BALB/c mice with
B. abortus 544 infection [24] and 1.26-log protection unit with B. abortus 2308 infection [32]. The protective efficacy of RB51 is very variable and could even reach up to 2.31$\log$ reduction [18]. Thus, this protective immunity is equivalent when compared to the lower range but does not surpass the higher range of protection conferred by RB51. Further investigation is warranted in improving the protective efficacy of this combination, such as the type of adjuvant to be used that can boost cell-mediated immunity, the dose of each Brucella antigen and the frequency of vaccination.

In summary, the combination of these five antigens predominantly boosted cellular immune responses and humoral immunity in a mouse model through upregulation of IFN- $\gamma$ and inhibition of IL-10 production that possibly contributed to protective immunity against brucellosis. Thus, this vaccine combination might be considered as a potential effective vaccine candidate for further development in the future.

\section{Acknowledgments}

This research was supported by a grant of the Korea Health Technology R\&D Project through the Korea Health Industry Development Institute (KHIDI), funded by the Ministry of Health \& Welfare, Republic of Korea (Grant number: HI16C2130).

\section{Conflict of Interest}

The authors have no financial conflicts of interest to declare.

\section{References}

1. Hop HT, Simborio HL, Reyes AW, Arayan LT, Min W, Lee HJ. 2015. Immunogenicity and protective effect of recombinant Brucella abortus Ndk (rNdk) against a virulent strain Brucella abortus 544 infection in BALB/c mice. FEMS. Microbiol. Lett. 362: 1-6.

2. Trujillo IZ, Zavala AN, Caceres JG, Miranda CQ. Brucellosis. 1994. Infect. Dis. Clin. North. Am. 8: 225-241.

3. Franco MP, Mulder M, Gilman RH, Smits HL. Human brucellosis. 2007. Lance. Infect. Dis. 7: 775-786.

4. Ko J, Splitter GA. 2003. Molecular host-pathogen interaction in brucellosis: current understanding and future approaches to vaccine development for mice and humans. Clin. Microbiol. Rev. 16: 65-78.

5. Corbel MJ. 1997. Brucellosis: an overview. Emerg. Infect. Dis. 3: 213-221. 
6. Sangari FJ, Aguero J. 1996. Molecular basis of Brucella pathogenicity: an update. Microbiologia 12: 207-218.

7. Baldwin CL, Winter AJ. 1994. Macrophages and Brucella. Immunol. Ser. 60: 363-380.

8. Ebel ED, Williams MS, Tomlinson SM. 2008. Estimating herd prevalence of bovine brucellosis in 46 USA states using slaughter surveillance. Prev. Vet. Med. 85: 295-316.

9. Treanor JJ, Johnson JS, Wallen RL, Cilles S, Crowley PH, Cox JJ, et al. 2010. Vaccination strategies for managing brucellosis in Yellowstone bison. Vaccine 28: F64-F72.

10. Galindo RC, de Miguel MJ, Labairu J, Marin CM, Revilla M, Blasco JM, et al. 2010. Gene expression changes in spleens of the wildlife reservoir species, Eurasian wild boar (Sus scrofa), naturally infected Brucella suis biovar 2. J. Genet. Genomics 37: 725-736.

11. Olsen SC, Hennayer SG. 2010. Immune responses and protection against experimental Brucella suis biovar 1 challenge in non-vaccinated cattle. Clin. Vaccine Immunol. 17: 1891-1895.

12. Perrie Y, Mohammed AR, Kirby DJ, McNeil SE, Bramwell VW. 2008. Vaccine adjuvant systems: enhancing the efficacy of sub-unit protein antigens. Int. J. Pharm. 364: 272-280.

13. Arena-Gamboa AM, Ficht TA, Kahl-McDonagh MM, RiceFicht AC. 2008. Immunization with a single dose of a microencapsulated Brucella melitensis mutant enhances protection against wild-type challenge. Immun. Infect. 76: 2448-255.

14. Rafiei A, Ardestani SK, Kariminia A, Keyhani A, Mohraz M, Armithani A. 2006. Dominant Th1 cytokine production in early onset of human brucellosis followed by switching towards Th2 along prolongation of disease. J. Infect. 53: 315324.

15. Reyes AWB, Simborio HLT, Huyhn TH, Arayan LT, Kim S. 2016. Molecular cloning, purification and immunogenicity of recombinant Brucella abortus 544 malate dehydrogenase protein. J. Vet. Sci. 17: 119-122.

16. Velikovsky CA, Goldbaum FA, Cassataro J, Estein S, Bowden RA, Bruno L, et al. 2003. Brucella lumazine synthase elicits a mixed Th1-Th2 immune response and reduces infection in mice challenged with Brucella abortus 544 independently of the adjuvant formulation used. Infect. Immun. 71: 5750-5755.

17. Stevens MG, Pugh G Jr, Tabatabai LB. 1992. Effects of gamma interferon and indomethacin in preventing Brucella abortus infections in mice. Infect. Immun. 60: 4407-4409.

18. Oliveira SC, Splitter GA. 1996. Immunization of mice with recombinant L7/L12 ribosomal protein confers protection against Brucella abortus infection. Vaccine 14: 959-962.

19. Dubray G, Bezard G. 1980. Isolation of three Brucella abortus cell wall antigens protective in murine experimental brucellosis. Ann. Rech. Vet. 11: 367-373.

20. Lim JJ, Kim DH, Kim DG, Kim DG, Min W, Lee HJ, et al. 2012. Protective effects of recombinant Brucella abortus
Omp28 against infection with a virulent strain of Brucella abortus 544 in mice. Vet. Sci. 13: 287-292.

21. Miranda KL, Dorneles EMS, Pauletti RB, Poester FP, Lage AP. 2015. Brucella abortus S19 and RB51 vaccine immunogenicity test: evaluation of three mice (BALB/c, Swiss and CD-1) and two challenge strains (544 and 2308). Vaccine 33: 507-511.

22. Schurig GG, Sriranganathan N, Corbel MJ. 2002. Brucellosis vaccines: past, present and future. Vet. Microbiol. 90: 479496.

23. Araya LN, Elzer PH, Rowe GE, Enright FM, Winter AJ. 1989. Temporal development of protective cell-mediated and humoral immunity in BALB/c mice infected with Brucella abortus. J. Immunol. 143: 3330-3337.

24. Pavlov HM, Hogarth IF, McKenzie F, Cheers C. 1982. In vivo and in vitro effects of monoclonal antibody to Ly antigens on immunity to infection. Cell. Immunol. 71: 127-138.

25. Truong QL, Cho Y, Kim K, Park BK, Hahn TW. 2015. Booster vaccination with safe, modified, live-attenuated mutants of Brucella abortus strain RB51 vaccine confers protective immunity against virulent strains of B. abortus and Brucella canis in BALB/c mice. Microbiology 161: 2137-2148.

26. Bachrach G, Banai M, Bardenstein S, Hoida G, Genizi A, Bercovier H. 1994. Brucella ribosomal protein L7/L12 is a major component in the antigenicity of Brucella in INRA for delayed-type hypersensitivity in Brucella-sensitized guinea pigs. Infect. Immun. 62: 5361-5366.

27. Gee J, Valderas MW, Kovach M, Grippe VK, Robertson GT, $\mathrm{Ng} \mathrm{WL}$, et al. 2005. The Brucella abortus $\mathrm{Cu}, \mathrm{Zn}$ superoxide dismutase is required for optimal resistance to oxidative killing by murine macrophages and wild-type virulence in experimentally infected mice. Infect. Immun. 73: 2873-2880.

28. Tabatai LB, Pugh GW. 1994. Modulation of immune responses in BALB/c mice vaccinated with Brucella abortus $\mathrm{Cu}-\mathrm{Zn}$ superoxide dismutase synthetic peptide vaccine. Vaccine 12: 919-924.

29. Piddington DL, Fang FC, Laessig T, Cooper AM, Orme IM, Buchmeier NA. 2001. Cu, Zn superoxide dismutase of Mycobacterium tuberculosis contributes to survival in activated macrophages that are generating an oxidative burst. Infect. Immun. 69: 4980-4987.

30. De Groote MA, Ochner UA, Shiloh MU Nathan C, McCord JM, Dinauer MC, Libby SJ, et al. 1997. Periplasmic superoxide dismutase protects Salmonella from products of phagocyte NADPH oxidase and nitric oxide synthase. Proc. Natl. Acad. Sci. USA 94: 13997-14001.

31. Velikovsky CA, Cassataro J, Giambartolomei GH, Goldbaum FA, Estein S, Bowden RA, et al. 2002. A DNA vaccine encoding lumazine synthase from Brucella abortus induces protective immunity in BALB/c mice. Infect. Immun. 70: 2507-2511.

32. Oliveira SC, Giambartolomei GH, Cassataro JC. 2011. Confronting the barriers to develop vaccines against brucellosis. Expert. Rev. Vaccines 10: 1291-1305. 
33. Godfroid J, Käsbohrer A. 2002. Brucellosis in the European Union and Norway at the turn of the twenty-first century. Vet. Microbiol. 90: 135-145.

34. Perkins SD, Smither SJ, Atkins HS. 2010. Towards a Brucella vaccine for humans. FEMS. Microbiol. Rev. 34: 379-394.

35. Fugier E, Pappas G, Gorvel JP. 2007. Virulence factors in brucellosis: implications for aetiopathogenesis and treatment. Expert. Rev. Mol. Med. 9: 1-10.

36. Jiang X, Baldwin CL. 1993. Iron augments macrophagemediated killing of Brucella abortus alone and in conjunction with IFN- $\gamma$. Cell. Immunol. 148: 397-407.

37. Luo D, Ni B, Li P, Shi W, Zhang S, Han Y. 2006. Protective immunity elicited by a divalent DNA vaccine encoding both the L7/L12 and Omp16 genes of Brucella abortus in BALB/c mice. Infect. Immun. 74: 2734-2741.

38. Motaharinia Y, Rezaee MA, Rashidi A, Jalili A, Rezaie MJ, Shapouri $R$, et al. 2013. Induction of protective immunity against brucellosis in mice by vaccination with a combination of naloxone, alum and heat-killed Brucella melitensis 16M. J. Microbiol. Immunol. Infect. 46: 253-258.

39. Cassataro J, Estein SM, Pasquevich KA, Velikovsky CA, de la Barrera S, Bowden R, et al. 2005. Vaccination with the recombinant Brucella outer membrane protein 31 or a derived 27-amino-acid synthetic peptide elicits a CD4+ T helper 1 response that protects against Brucella melitensis infection. Infect. Immun. 73: 8079-8088.

40. Pasquevich KA, Estein SM, Garcia-Samartino C, Zwerdling A, Coria LM, Barrionuevo P, et al. 2009. Immunization with recombinant Brucella species outer membrane protein Omp16 and Omp19 in adjuvant induces specific CD4+ and CD8+ T cells as well as systemic and oral protection against Brucella abortus infection. Infect. Immun. 77: 436-445.

41. Couper KN, Blount DG, Riley EM. 2008. IL-10; the master regulator of immunity to infection. J. Immunol. 180: 5771-5777.

42. Fernandez DM, Baldwin CL. 1995. Interleukin-10 downregulates protective immunity to Brucella abortus. Infect. Immun. 63: 1130-1133.

43. Corsetti P, de Almeida L, Carvalho N, Azevedo V, Teane S, Texeira H, et al. 2013. Lack of endogenous IL-10 enhances production of proinflammatory cytokines and leads to Brucella abortus clearance in mice. PLoS One 8: e74729.

44. Hop HT, Arayan LT, Tran Xuan H, Reyes AW, Kim S. 2018. Immunization of BALB/c mice with a combination of four recombinant Brucella abortus proteins, AspC, Dps, InpB and $\mathrm{Ndk}$, confers a marked protection against a virulent strain of Brucella abortus. Vaccine 36: 3027-3033. 